\title{
Digital Storytelling e formação corporativa: possibilidades para a aprendizagem de adultos
}

Josias Ricardo Hack

Professor adjunto da Universidade Federal de Santa Catarina.

E-mail: professor.hack@hotmail.com

Fernando Ramos

Professor catedrático da Universidade de Aveiro (Portugal).

E-mail: fernando.ramos@ua.pt

Arnaldo Santos

Engenheiro da direşão de inovação exploratória da Portugal Telecom Inovação Portugal.

E-mail: arnaldo@ptinovacao.pt

Resumo: Neste artigo, discutimos o uso de estratégias de aprendizagem colaborativa baseadas em tecnologias audiovisuais digitais num contexto de capacitação corporativa. O texto tem início com uma revisão concisa sobre os fundamentos teóricos e técnicos da comunicação educativa, por meio do uso de produtos audiovisuais. Em seguida, explicitamos como o uso de histórias pessoais digitais pode contribuir com os processos de aprendizagem colaborativa em treinamentos corporativos, oferecendo meios para a entrega rápida de materiais contextualizados que permitam a partilha de experiências entre formandos e formadores. Por fim, concluímos que o uso de histórias pessoais digitais pode ser uma oportunidade para se incrementar interações múltiplas no processo de construção do conhecimento corporativo.

Palavras-chave: Digital Storytelling; tecnologias digitais; Comunicação; capacitação corporativa.
Abstract: In this paper we discuss the use of collaborative learning strategies based on Digital Storytelling in corporative training. The text includes a concise review on theoretical and technical basis about educational communication through the use of audiovisual products. The paper will also argue that digital storytelling may contribute to the improvement of the effectiveness of collaborative learning processes in corporative training, providing swift delivery of highly contextualized learning materials, which allows the sharing of relevant personal experiences between trainers and trainees. Furthermore, we conclude that Digital Storytelling provides an opportunity to value, respect and promote the multiple and different cultural and social interactions in the corporative knowledge construction process.

Keywords: Digital Storytelling; Digital technologies; Communication; Corporative training. 
1. VYGOTSKY, Lev S. Pensamento e linguagem. São Paulo: Martins Fontes, 1993, p. 38.

2. SCHANK, Roger C. Lessons in learning e-learning, and training: Perspectives and guidance for the enlightened trainer [Lições em aprendizagem, e-learning e treinamento: perspectivas e orientação para o educador esclarecido]. San Francisco: Pfeiffer 2005, p. 57.

3. VYGOTSKY, Lev S. Pensamento e linguagem, cit., p. 38.

4. JONASSEN, David. H.; HERNANDEZ-SERRANO,

Julien. Case-based reasoning and instructional design using stories to support problem solving [Raciocínio baseado em casos e design instrucional usando histórias para apoiar a resolução de problemas]. Educational Technology Research and Development, 50, n. 2, p. 7-8, 2002

5. VYGOTSKY, Lev $S$. Pensamento e linguagem, cit., p. 46.

6. VYGOTSKY, Lev S. et al. Linguagem, desenvolvimento e aprendizagem São Paulo: Ícone, 1988, p. 117-118.

7. FRAZEL, Midge. Digital Storytelling: guide for educators [Digital Storytelling: guia para educadores]. Washington, DC: ISTE, 2010, p. 36-37. comunicação \& educação • Ano XVIII • número 1 • jan/jun 2013

\section{INTRODUÇÃO}

$\mathrm{O}$ ato de contar histórias está intimamente associado ao senso de identidade dos povos, ${ }^{1}$ constituindo-se ainda em um dos componentes fundamentais da memória humana e em fundamento de vários eventos mentais básicos² Vygotsky $^{3}$ afirmou que, para entender e representar sua experiência no mundo, as pessoas fazem uso de linguagens compostas por signos, que acabam por formar a base da cultura humana. $\mathrm{O}$ autor destaca, inclusive, que as ferramentas que construímos para mediar essas atividades simbólicas mudam a maneira pela qual os seres humanos pensam. Em outras palavras, através da construção de ferramentas, as pessoas constroem a base material para a consciência, transformando os ambientes e reestruturando os sistemas funcionais em que atuam e aprendem. Ao fazer isso, lançam-se trajetórias de desenvolvimento do pensamento e da ação que repercutem amplamente, abrangendo as dimensões individual e coletiva, material e semiótica.

O processo descrito anteriormente é o que pode ocorrer, em nossa interpretação, com a introdução do Digital Storytelling (doravante denominado DS) no cotidiano - já que seu ponto de partida é a vivência individual, sendo seu principal objetivo propiciar um espaço de enunciação e narrativa sobre as próprias vivências, provocando reflexões a respeito das conquistas e das derrotas que cada indivíduo experimentou em sua caminhada. Dentro das atividades de DS, os participantes gravam pequenas narrativas de vida em primeira pessoa, ilustradas com fotos, imagens, gravuras e músicas significativas para si. Por meio da socialização da história digital produzida individualmente, podem ter início trajetórias coletivas e colaborativas de desenvolvimento do pensamento e da ação.

No que tange ao uso do recurso de DS em contextos de ensino e aprendizagem, Jonassen e Hernandez-Serrano ${ }^{4}$ sugerem três maneiras de apoio ao processo de construção do conhecimento com o uso de histórias digitais. Elas podem exemplificar determinados conceitos ou princípios ensinados por instrução direta; podem servir como casos ou problemas a serem investigados pelos alunos; ou, numa terceira hipótese, podem possibilitar o acesso dos alunos a informações que os ajudarão a resolver problemas. Vale lembrar que, segundo Vygotsky $^{5}$, a interação social é imprescindível para a aprendizagem e o desenvolvimento do ser humano, pois as pessoas adquirem novos saberes a partir das várias relações com o ambiente que as cerca.

Na concepção sócio-histórica ${ }^{6}$, a mediação é primordial na construção do conhecimento - ocorrendo, dentre outras formas, pela linguagem. A singularidade do indivíduo enquanto sujeito sócio-histórico se constitui em suas relações na sociedade, enquanto o modo de pensar ou agir das pessoas depende de interações sociais e culturais com o ambiente. Isto quer dizer que um grande contador de histórias pode evocar uma ligação emocional com seus ouvintes, contribuindo com o processo de construção do conhecimento.

Para $\mathrm{Frazel}^{7}$, a ligação pessoal entre o público e o contador de histórias é emocionalmente carregada de contato visual, linguagem corporal e narração. 
Segundo a autora, conectar-se com uma plateia e trazê-la para dentro da história pode ser uma experiência profundamente gratificante para estudantes e professores.

Em suma, como vimos nessas breves linhas introdutórias e como também apontou Barret ${ }^{8}$, a narração com tecnologias digitais facilita a convergência de estratégias diferenciadas de aprendizagem e, se bem equacionada, poderá promover:

- o envolvimento dos aprendizes;

- a reflexão para o aprendizado profundo;

- a aprendizagem baseada em projetos;

- a integração efetiva da tecnologia na instrução.

No entanto, apesar deste potencial, o DS é aparentemente subutilizado em contextos de aprendizagem de adultos em formação corporativa.

\section{APRENDIZAGEM DE ADULTOS}

Vygostsky ${ }^{9}$ enunciou que, quando uma pessoa ata um nó em um lenço para ajudá-la a se lembrar de algo, está, essencialmente, concluindo o processo de memorização. Em outras palavras, ela transforma o processo de lembrança numa atividade externa. Para o autor, a verdadeira essência da memória humana está no fato de os seres humanos serem capazes de se lembrar de algo, ativamente, com a ajuda de signos. Poder-se-ia dizer que a característica básica do comportamento humano, em geral, é que as pessoas influenciam sua própria relação com o ambiente, bem como modificam seu comportamento através desse ambiente.

$\mathrm{Na}$ concepção de $V_{y g o t s k y}{ }^{10}$, a interação social é uma peça essencial no processo de aprendizagem e no desenvolvimento do ser humano, já que as pessoas adquirem novos saberes a partir de suas várias relações sociais. No entanto, ainda é preciso aprofundar a compreensão de como se processa a construção desse conhecimento.

Segundo Knowles ${ }^{11}$, tradicionalmente nós sabemos mais sobre como os animais aprendem do que sobre como as crianças aprendem, bem como sabemos muito mais sobre como as crianças aprendem do que sobre como os adultos aprendem.

Para o autor, tal cenário se configurou assim, possivelmente, devido ao fato de o estudo da aprendizagem ter sido assumido, inicialmente, por psicólogos experimentais cujos cânones exigiam o controle de variáveis. Além disso, é comprovado que as condições em que os animais aprendem são mais controláveis do que aquelas sob as quais as crianças aprendem. Também as condições em que as crianças aprendem, por sua vez, são muito mais controláveis do que aquelas sob as quais os adultos aprendem. Em síntese, o fato é que muitas das teorias da aprendizagem derivam do estudo da aprendizagem de animais e crianças.
8. BARRETT, Helen. Researching and evaluating Digital Storytelling as a deep learning tool [Pesquisando e avaliando o Digital Storytelling como uma vasta ferramenta de aprendizagem]. In C. Crawford, et al. (ed.). Proceedings of Society for Information Technology and Teacher Education International [Anais da Sociedade para Tecnologia da Informação e do Ensino de Educação Internacional]. Chesapeake: AACE, 2006, p. 648.

9. VYGOTSKY, Lev S. et al. Linguagem, desenvolvimento e aprendizagem, cit., p. 68.

10. Ibid., p. 70.

11. KNOWLES, Malcolm S.; HOLTON, Elwood F.; SWANSON, Richard A. The adult learner: the definitive classic in Adult Education and Human Resource Development [O aluno adulto: o clássico definitivo em Educação de Adultos e o Desenvolvimento de Recursos Humanos]. Woburn: Butterworth-Heinemann, 1998, p. 18. 
comunicação \& educação • Ano XV|II • número 1 • jan/jun 2013

Knowles $^{12}$ ainda nos lembra de que alguns dos grandes mestres dos tempos antigos - Confúcio e Lao Tse, na China; Jesus e os profetas hebreus, nos textos bíblicos; Aristóteles, Sócrates e Platão, na antiga Grécia; e Cícero, Evelid e Quintiliano, na Roma antiga - foram todos professores de adultos, não de crianças. Dessa forma, a partir de suas experiências com os adultos, desenvolveram um conceito muito específico de ensino e aprendizagem, considerando-os como um processo de investigação mental e não como recepção passiva de conteúdos difundidos. As técnicas desenvolvidas por eles, portanto, são voltadas a envolver os alunos no processo de investigação.

Os antigos chineses e hebreus inventaram o que hoje chamamos de método do caso, em que o líder ou um dos membros do grupo descreve uma situação muitas vezes na forma de uma parábola - e, juntamente com o grupo, explora suas características e possíveis resoluções. Os gregos, por sua vez, inventaram o que hoje chamamos diálogo socrático, em que o líder ou um membro do grupo coloca uma questão ou dilema para que se possa buscar uma resposta ou solução. Já os romanos usaram técnicas de confrontação: propunham desafios aos membros do grupo, que eram forçados a pensar em suas posições para defendê-las.

O modelo andragógico (para aprendizagem de adultos), proposto por Knowles ${ }^{13}$, também é baseado em suposições diferentes das do modelo pedagógico (para aprendizagem de crianças). Segundo o autor, os adultos precisam saber por que é necessário aprender algo antes de iniciar a aprendizagem. Quando os adultos se comprometem a aprender algo por conta própria, investem considerável energia na sondagem dos benefícios que irão obter com a aprendizagem e das consequências negativas de não aprender.

Sendo assim, a primeira tarefa do facilitador é a de ajudar o aluno a tomar consciência da necessidade de saber. Uma boa estratégia para aumentar o nível dessa consciência é o uso de experiências reais ou simuladas em que os alunos descobrem, por si mesmos, as diferenças entre o estágio em que estão agora e aquele onde querem chegar. Frisamos que, embora eles saibam aonde querem chegar, a presença de um mediador é de extrema importância, podendo ser esse mediador o contador de histórias.

Para Knowles, os adultos se motivam a aprender quando percebem que o novo conhecimento os ajudará a lidar eficazmente com situações enfrentadas em seu cotidiano. Além disso, aprendem novos conhecimentos, habilidades, valores e atitudes de forma mais eficaz quando tais questões são apresentadas de modo contextualizado. $\mathrm{O}$ autor explica, ainda, que mesmo que alguns adultos sejam sensíveis a motivadores externos de aprendizagem (possibilidade de conseguir um novo emprego, promoções, salários mais elevados e assim por diante), os motivadores mais potentes são pressões internas (o desejo de maior satisfação

12. Ibid., p. 35-36.

13. Ibid., p. 62-69.

14. Ibid., p. 40. no trabalho, autoestima, qualidade de vida).

Em suma, o processo de aprendizagem do adulto, defendido por Knowles ${ }^{14}$, se fundamenta nos seguintes aspectos: 
- Os adultos são motivados a aprender coisas que satisfaçam necessidades e interesses imediatos. Portanto, estes são os pontos de partida adequados à organização de atividades de aprendizagem de adultos.

- A orientação dos adultos para a aprendizagem é centrada na vida cotidiana. Dessa forma, as unidades apropriadas para organizar a aprendizagem de adultos são situações da vida, não temas.

- A experiência é o mais rico recurso para a aprendizagem dos adultos. Por isso, a metodologia central da educação de adultos deve ser a análise de experiências.

- Os adultos têm uma profunda necessidade de se autodirigir. Portanto, o papel do professor é engajar-se em um processo de investigação mútua com seus alunos, ao invés de transmitir seu conhecimento a eles e, em seguida, avaliar sua conformidade.

- As diferenças individuais entre as pessoas aumentam com a idade. Dessa forma, a educação de adultos deve prever diferenças de estilo, tempo, lugar e ritmo de aprendizagem.

Como veremos na próxima seção, a utilização de histórias digitais em processos de formação de adultos pode oferecer uma oportunidade para a promoção de interações múltiplas (colaborações) no processo de construção do conhecimento - uma vez que, através de histórias pessoais, os formadores e formandos discutirão assuntos centrados em suas próprias experiências que satisfaçam suas necessidades e interesses imediatos.

\section{DS NO CONTEXTO CORPORATIVO}

A pesquisa qualitativa que originou o presente artigo analisou casos brasileiros e portugueses sobre o uso do DS em contexto corporativo. Ao todo, foram sondados 111 artigos acadêmicos e 9 livros abordando a temática DS em algum âmbito. Os artigos internacionais foram obtidos nas bases eletrônicas de dados SciVerse Scopus (banco de dados pertencente à Elsevier) e B-on (Biblioteca do Conhecimento On-line das instituições de investigação e de ensino superior em Portugal). O corte temporal da análise teve a seguinte definição: a) artigos publicados em 2008, 2009, 2010 e primeiro semestre de 2011; b) livros publicados nos últimos 10 anos.

Durante o estudo bibliográfico, percebemos que o ato de contar histórias com tecnologias digitais tem sido largamente explorado por publicitários para alavancar um produto ou empresa. Em alguns casos, o DS é utilizado para provocar no consumidor a identificação com o narrador ou com um dos personagens da história. Já em outras experiências, as corporações dão suporte, inclusive, à criação de comunidades de consumidores em redes sociais. Também 
comunicação \& educação • Ano XV|l| • número 1 • jan/jun 2013

foi possível encontrar relatos de uso do DS para a motivação de equipes, principalmente de vendas.

No que tange ao uso de narrativas digitais em contextos de capacitação corporativa, Savvidou (2010) destaca a importância do conceito de "diálogo" na narrativa. Segundo a autora, embora seja dada pouca atenção ao conceito de narrativa como um diálogo em contextos educacionais, esta é uma rica frente de investigação no âmbito da pesquisa organizacional e comunicacional. Nesta área, o ato de contar histórias é representado como uma prática social compartilhada, através da qual o conhecimento explícito e tácito pode ser transmitido e as identidades adquiridas.

O conceito de narrativa que Savvidou ${ }^{15}$ apresenta em seu texto está ancorado em teorias de comunicação verbal e na ideia de que contar histórias é, inerentemente, um ato dialógico - de modo que, sempre que uma história é contada, provoca uma resposta. Em outras palavras, as histórias que contamos são moldadas pelas respostas reais ou potenciais dos interlocutores. Essa ideia representa uma visão de narrativa como forma de diálogo, desafiando a noção de história como construção individual.

Savvidou $^{16}$ salienta que, se observarmos as interações sociais cotidianas, verificaremos que o ato de contar histórias pessoais não é apresentado como monólogo, mas sim como parte de um evento interacional, uma conversa na qual histórias são mutuamente construídas pelos participantes. Neste processo, inclusive os papéis de contador da história e destinatário são intercambiáveis.

Para a autora, dentro do campo da pesquisa organizacional e comunicacional, os estudos incluem frequentemente as histórias de pessoas cujas vozes raramente são ouvidas, ou que desafiam as normas vigentes e as estruturas organizacionais.

Em toda corporação, podem-se ouvir histórias que permeiam sua existência e solidificam comportamentos específicos de seus colaboradores. Em nossa interpretação, tais histórias podem ser contadas no formato digital e utilizadas favoravelmente em contextos de formação corporativa para: a) comunicar a missão, os objetivos e as políticas corporativas; b) mobilizar e fomentar o espírito de equipe; c) envolver as pessoas em determinadas ações estratégicas; d) proporcionar a estruturação e divulgação da memória corporativa; e) fortalecer valores e traços característicos da corporação; e f) outras possibilidades que o próprio leitor poderá enumerar.

Apesar de nossos estudos identificarem o uso de DS em organizações no Brasil e em Portugal, a investigação não encontrou nenhum relato que explicitasse a utilização da narratividade digital em contexto de ensino e aprendizagem corporativos. Entretanto, ficou patente em nossas leituras a importância de se realizar uma reflexão ampla sobre os conteúdos a serem transformados em roteiros de DS, bem como a necessidade de se pensar em estratégias audiovisuais que desencadeiem percepções semelhantes às de origem natural, ao se centrarem em desenvolver códigos e convenções sígnicas não arbitrárias ${ }^{17}$. 
Tais estratégias audiovisuais, em nossa interpretação, podem potencializar a comunicação do conhecimento, bem como contribuir para a melhoria da eficácia de alguns processos de treinamento corporativo. Afinal, devido às características ágeis de concepção e produção de audiovisuais com a aplicação do DS, existe a possibilidade de se oferecerem meios para a rápida entrega de materiais educativos altamente contextualizados.

Consideramos relevante destacar que introduzir o DS no ambiente de formação corporativa não é uma decisão meramente instrumental. Para Porter ${ }^{18}$, há muito a se considerar na construção de uma história digital - já que existem abordagens infinitas, dependendo da finalidade e do público que se quer atingir. Àqueles que pretendem utilizar este estilo de narrativa, a autora chama a atenção para alguns procedimentos fundamentais:

- Deve-se levar os outros a vivenciarem sua história. Em outras palavras, cada história tem uma perspectiva pessoal e precisa ser narrada pelo próprio autor.

- Trazer sempre uma lição a ser aprendida. Uma das características mais originais do DS é a expectativa de que cada história expresse um significado pessoal ou insight sobre como um determinado evento ou situação tocou a vida do autor (e quiçá poderá tocar a vida dos ouvintes).

- Desenvolver uma tensão criativa. Uma boa história cria intriga ou tensão em torno de uma situação que se coloca já em seu início, sendo desenvolvida no decorrer da trama.

- Ser econômico. Uma boa história tem um destino, um objetivo a cumprir e procura o caminho mais curto para chegar a ele. Uma peça de DS deve ter entre 3 e 5 minutos, com base em um roteiro de uma página ou 500 palavras.

- Mostrar e não apenas narrar uma história. Boas histórias usam detalhes vívidos para revelar sentimentos e informações, ao invés de apenas dizer algo.

- Ser técnica e, ao mesmo tempo, uma obra de arte. Uma boa história incorpora a tecnologia e a arte de forma astuta, ao demonstrar habilidade em se comunicar com imagens, som, voz, cor, espaços em branco, animações, design, transições e efeitos especiais.

Por fim, nossos estudos também identificaram que o DS pode oferecer uma oportunidade para a promoção de interações múltiplas no processo de construção do conhecimento em ambientes corporativos. Por exemplo, em certas propostas de formação em uma organização, poder-se-á introduzir tarefas, via DS, que provoquem os formandos à partilha de suas próprias histórias novamente via DS. Assim, tanto formadores quanto formandos colaborarão na aprendizagem por meio de curtos relatos digitais em uma via de mão dupla.
18. PORTER, Bernajean. DigiTales: the art of telling digital stories [DigiTales: a arte de conta histórias digitais]. Sedalia: Porter, 2004, p. 115. 


$$
\text { comunicação \& educação • Ano XVIII • número } 1 \text { • jan/jun } 2013
$$

Em síntese, a pesquisa sinaliza que o processo comunicacional dialógico, que utiliza estratégias de aprendizagem colaborativa, pode ser uma alternativa para a valorização e o respeito às múltiplas interações sociais e culturais dos envolvidos no contexto de formação - desempenhando, dessa forma, o papel de alavanca dos movimentos individuais e coletivos de aprendizagem, tão salutares no processo de construção do conhecimento em qualquer nível ou modalidade de ensino.

\section{CONSIDERAÇÕES FINAIS}

Atualmente qualquer cidadão, desde que tenha acesso e saiba utilizar determinadas tecnologias e técnicas, pode contar a sua própria história digitalmente. No contexto educacional e de formação corporativa, tal potencialidade redimensiona a necessidade de produção audiovisual por equipes altamente especializadas - e aponta a possibilidade de dar voz e visibilidade às histórias digitais elaboradas por aqueles que estão nas duas pontas do processo de ensino e aprendizagem: o aluno/formando e seu professor/formador.

Nosso intuito, ao elaborar o presente artigo, foi refletir sobre o DS em processos de construção do saber nas organizações. O documento foi baseado em pesquisa bibliográfica qualitativa e argumentou que o DS pode contribuir para a melhoria da eficácia dos processos de ensino em treinamento corporativo, oferecendo meios para a entrega rápida de materiais de aprendizagem altamente contextualizados. Além disso, o uso da narratividade digital pode constituir-se em oportunidade para a promoção de interações múltiplas no processo de construção do conhecimento nas organizações, introduzindo, em certas propostas de capacitação, estratégias que incentivem a partilha de histórias digitais entre formadores e formandos, numa "via de mão dupla".

Por fim, queremos enfatizar a necessidade de a comunidade científica dar atenção à investigação sobre a questão do uso de histórias digitais pessoais em formação corporativa. Percebemos, por meio dessa pesquisa, que suas possibilidades são múltiplas e devem abranger discussões epistemológicas, metodológicas, tecnológicas, operacionais, éticas e legais.

A título de ilustração, mencionamos nosso projeto atual, uma parceria entre a Universidade de Aveiro (Portugal) e a Portugal Telecom, que visa operacionalizar e validar uma metodologia de utilização de histórias digitais pessoais em contexto de formação profissional, através da reflexão crítica e experimentação empírica. O intuito do projeto é desenvolver roteiros de pequenas histórias pessoais digitais, produzi-los e testar a eficiência e eficácia do uso de tais vídeos em ambientes de ensino e aprendizagem corporativa. 


\section{REFERÊNCIAS BIBLIOGRÁFICAS}

BARRETT, Helen. Researching and evaluating Digital Storytelling as a deep learning tool [Pesquisando e avaliando o Digital Storytelling como uma vasta ferramenta de aprendizagem]. In: CRAWFORD, C. et al. (ed.). Proceedings of Society for Information Technology and Teacher Education International [Anais da sociedade para tecnologia da informação e do ensino de educação internacional]. Chesapeake: AACE, 2006.

FRAZEL, Midge. Digital Storytelling: guide for educators [Digital Storytelling, guia para educadores]. Washington, DC: ISTE, 2010.

JONASSEN, David. H.; HERNANDEZ-SERRANO, Julien. Case-based reasoning and instructional design using stories to support problem solving [Raciocínio baseado em casos e design instrucional usando histórias para apoiar a resolução de problemas]. Educational Technology Research and Development, 50, n. 2, 2002.

KEARNEY, M. A learning design for student-generated digital storytelling [Um projeto de aprendizagem para estudantes gerarem suas histórias digitais]. Learning, Media and Technology, v. 36, n. 2, p. 169-188, 2011.

KNOWLES, Malcolm S.; HOLTON, Elwood F.; SWANSON, Richard A. The adult learner: the definitive classic in Adult Education and Human Resource Development [O aluno adulto: o clássico definitivo em Educação de Adultos e o Desenvolvimento de Recursos Humanos]. Woburn: Butterworth-Heinemann, 1998.

PORTER, Bernajean. DigiTales: the art of telling digital stories [DigiTales: a arte de contar histórias digitais]. Sedalia: Porter, 2004.

POSTMAN, Neil. Learning by story [Aprendendo pela história]. The Atlantic, 1989.

RODRIGUEZ, Angel. A dimensão sonora da linguagem audiovisual. São Paulo: Senac, 2006.

SAVVIDOU, Christine. Storytelling as dialogue: how teachers construct professional knowledge [Storytelling como diálogo: como professores constroem conhecimento professional]. Teachers and Teaching, 16, n. 6, 2010.

SCHANK, Roger C. Lessons in learning, e-learning, and training: perspectives and guidance for the enlightened trainer [Lições em aprendizagem, e-learning e treinamento: perspectivas e orientação para o educador esclarecido]. San Francisco: Pfeiffer, 2005.

VYGOTSKY, Lev S. et al. Linguagem, desenvolvimento e aprendizagem. São Paulo: Ícone, 1988.

Pensamento e linguagem. São Paulo: Martins Fontes, 1993. 